\title{
Research on Power Grid Infrastructure Investment Distribution Model Based on Entropy Weight Method
}

\author{
Yun Wang ${ }^{1}$, Jian Yaling ${ }^{2}$, Jie Yang ${ }^{3}$, YimingTang ${ }^{4}$, Ping Zhou ${ }^{5}$, Chao Chen ${ }^{6, a^{*}}$ \\ ${ }^{1}$ Economic and Technological Research Institute, State Grid Sichuan Electric Power Company Chengdu, China \\ ${ }^{2}$ Economic and Technological Research Institute, State Grid Sichuan Electric Power Company Chengdu, China \\ ${ }^{3}$ Economic and Technological Research Institute, State Grid Sichuan Electric Power Company Chengdu, China \\ ${ }^{4}$ Economic and Technological Research Institute, State Grid Sichuan Electric Power Company Chengdu, China \\ ${ }^{5}$ Economic and Technological Research Institute, State Grid Sichuan Electric Power Company Chengdu, China \\ ${ }^{6}$ School of Economics and Management, North China Electric Power University Beijing, China.
}

\begin{abstract}
With the development of the national economy, the scale of investment in power grid infrastructure has gradually expanded. The contradiction between the development of high-intensity investment, rigid growth in cost, slowing down of electricity growth, and difficulty in benefit growth has become increasingly prominent. The results show that the model can improve the scientificity and rationality of power grid infrastructure investment allocation under the background of operating constraints and capital constraints.
\end{abstract}

\section{Introduction}

In recent years, China's power grid investment has increased year by year, and the scale of power grid assets has increased significantly. However, due to changes in the external environment and the continued decline of the macro economy, high-speed investment has no longer conformed to the current operating conditions of power grid companies, and investment strategies need to be readjusted to adapt to changes in the new situation.

In recent years, there has been abundant research on the precise investment allocation of power grids. Literature [1] comprehensively analyzes the internal and external factors that affect the investment capacity of power grid companies and their relationships, and uses historical financial data and future forecast data to construct a model based on investment capacity. This paper provide a reference for the scientific and reasonable investment structure allocation of power grid enterprises. Reference [2] refers to the process of investment allocation of power grid companies, and proposes an iterative allocation model of distribution network investment that combines historical investment results. Literature [3] by thorough analysis of each Effects grid business investment factors, sort and summarize, building enterprise investment allocation model grid analysis from investment demand, investment capacity, investment returns and investment management in four areas Hierarchy Process, the grid companies Investment management provides effective reference.

Document [4] proposes a neural network algorithm score indicators rural power grid simulation function, to determine a total evaluation score of rural power grid, and defines the allocation rural power grid. Literature [5] innovatively introduced the concept of Gini coefficient, which is widely used in the field of national income distribution and environmental governance. Through the selection of key control indicators and the calculation of information entropy weights, it designed an investment allocation optimization scheme based on Gini coefficient. Literature [6] Factors sort Gudingzichan investment, through a comprehensive plan to optimize balance, build capacity to adapt to the investment calculation model of the power system. On this basis, the method of combining qualitative and quantitative is used to construct an investment allocation model.

To sum up, many electric power companies have paid enough attention to the management of physical assets, and there are a lot of exploration and practice in the management of physical assets, but they are unable to keep up with the rapid expansion of the number of equipment assets. They have an overall status and development trend of physical assets. Real-time and effective dynamic monitoring cannot be carried out. This article first builds a scientific and reasonable evaluation index system, and then uses the combination weight TOPSIS theory to carry out the diagnosis and evaluation of physical assets, which can provide a reference for the benefit improvement and efficiency improvement of power grid enterprises.

\section{Construction of investment allocation index system}

\subsection{Principles of constructing indicator system}

In the process of building an evaluation index system for

a*corresponding author Email: hbbdcc@126.com 
physical assets, the following four principles need to be followed.

The establishment of the physical asset evaluation index system should stand at the height of the company's overall situation, and comprehensively reflect the efficiency of the company's overall asset operation by summarizing the results of the subordinate units' asset scale structure, asset health level, asset utilization efficiency and asset retirement and retirement. And benefits.

The establishment of the physical asset evaluation index system not only depends on the detailed analysis of the physical assets of the company's subordinate units, but also is independent of the detailed analysis, grasps the principle of differentiation, and carries out targeted analysis around the changes and problems of the indicator data to ensure the analysis The objectivity and applicability of the results.

The evaluation indicators of physical assets need to closely focus on the original data in the business information system, unify the caliber and scope of data collection, and continuously improve the quality of the original data, so as to ensure that the indicator data is effective, complete and accurate. In the future, conditions are mature, and index results can be generated by automatically extracting information system data to achieve objective and efficient evaluation and analysis

Table1. Investment scale indicator system of county power grid companies

\begin{tabular}{|c|c|c|c|}
\hline Serial number & Index category & Indicator name & unit \\
\hline 1 & \multirow{2}{*}{ Economic and social indicators } & Population & Ten thousand people \\
\hline 2 & & Power supply area & Square kilometers \\
\hline 3 & \multirow{3}{*}{ Stock scale indicator } & Line length & $\mathrm{km}$ \\
\hline 4 & & $\begin{array}{l}\text { Distribution transformer } \\
\text { capacity }\end{array}$ & Ten MVA \\
\hline 5 & & $\begin{array}{l}\text { Distribution transformer } \\
\text { capacity per household }\end{array}$ & KVA/household \\
\hline 6 & \multirow{2}{*}{ Incremental Development Index } & $\begin{array}{c}\text { Proportion of electricity } \\
\text { sales growth }\end{array}$ & $\%$ \\
\hline 7 & & $\begin{array}{l}\text { New business expansion } \\
\text { capacity }\end{array}$ & Ten MVA \\
\hline 8 & \multirow{2}{*}{ Grid operation indicators } & Line load ratio & $\%$ \\
\hline 9 & & Transformer load ratio & $\%$ \\
\hline 10 & \multirow{2}{*}{ Operating efficiency indicators } & Net profit & Ten thousand yuan \\
\hline 11 & & Investment income ratio & $\%$ \\
\hline
\end{tabular}

\section{Construction of investment allocation evaluation model}

\subsection{Index weight calculation method}

Generally speaking, if the information entropy of an indicator is smaller, it indicates that the degree of variation of the indicator's value is greater, the more information provided, the greater the role it can play in the comprehensive evaluation, and the greater its weight. On the contrary, the larger the information entropy of an conclusions of physical assets.

The physical asset evaluation index must not only meet the management needs of physical asset evaluation, but also adapt to the overall strategy of State Grid asset management. With the changes in the internal and external environment of enterprise development, there is room for continuous adjustment and optimization of the evaluation index system.

\subsection{Establishment of investment allocation index system}

In order to accurately grasp the investment scale of power grid companies and establish a scientific investment scale model, we will combine qualitative and quantitative research on the indicator system of power grid company investment scale. The indicator of the investment scale of the grid company will greatly affect the formulation of the investment plan, mainly considering the economic and social conditions of each region and the actual status of the power grid (including the scale of the grid stock, the growth of electricity consumption, and the operation of the power grid), as well as the consideration of investment benefits. The operating conditions and other factors, the index system is shown below. 
solution. The TOPSIS method has no strict restrictions on the data distribution, sample size, and index. The original data is fully utilized and the information loss is relatively small. This method introduces the good value and bad value in the actual sample into the evaluation model through the determination of the positive ideal solution and the negative ideal solution, so that the evaluation result fully reflects the group characteristics of the evaluated object, so that the evaluation result is more objective. An effective multi-index, multi-objective decision analysis method. Sorting is based on the relative distance between the index vector of the evaluation object and the positive ideal solution and the negative ideal solution. If the evaluation object is close to the positive ideal solution and the farthest away from the negative ideal solution, it is the best; otherwise, it is not optimal.

As the name implies, the ideal solution does not exist in reality. It is an ideal solution to represent the optimal solution through virtuality. It represents the state that the decision maker most wants to achieve for the evaluation object.

The negative ideal solution is the opposite of the positive ideal solution. It is the worst solution assumed, and this solution does not necessarily exist. It represents the state that the decision makers most want to achieve for the evaluation object.

The advantage of the TOPSIS method is that due to the need to normalize the index data, the requirements for the original data are lower, and it will not adversely affect the evaluation results due to the number and unit of the

Table2. Table of original statistics

\begin{tabular}{|c|c|c|c|c|c|c|c|c|c|c|c|c|}
\hline \multirow[t]{2}{*}{$\begin{array}{c}\text { Serial } \\
\text { number }\end{array}$} & \multirow[t]{2}{*}{$\begin{array}{c}\text { company } \\
\text { name }\end{array}$} & Population & $\begin{array}{l}\text { Power } \\
\text { supply } \\
\text { area }\end{array}$ & $\begin{array}{l}\text { Line } \\
\text { length }\end{array}$ & $\begin{array}{c}\text { Distribution } \\
\text { transformer } \\
\text { capacity }\end{array}$ & $\begin{array}{l}\text { Distribution } \\
\text { transformer } \\
\text { capacity per } \\
\text { household }\end{array}$ & $\begin{array}{c}\text { Proportion } \\
\text { of } \\
\text { electricity } \\
\text { sales } \\
\text { growth }\end{array}$ & $\begin{array}{c}\text { New } \\
\text { business } \\
\text { expansion } \\
\text { capacity }\end{array}$ & $\begin{array}{l}\text { Line } \\
\text { load } \\
\text { ratio }\end{array}$ & $\begin{array}{c}\text { Transformer } \\
\text { load ratio }\end{array}$ & $\begin{array}{c}\text { Net } \\
\text { profit }\end{array}$ & $\begin{array}{c}\text { Investment } \\
\text { income } \\
\text { ratio }\end{array}$ \\
\hline & & $\begin{array}{c}\text { Ten } \\
\text { thousand } \\
\text { People }\end{array}$ & $\begin{array}{c}\text { Square } \\
\text { kilometers }\end{array}$ & $\mathrm{km}$ & 10MVA & KVA/household & $\%$ & 10MVA & $\%$ & $\%$ & $\begin{array}{c}100 \\
\text { million } \\
\text { yuan }\end{array}$ & $\%$ \\
\hline 1 & A & 36.48 & 1241 & 44.33 & 15567 & 4.48 & 7.8 & 5.72 & 5.65 & 0.24 & 0.29 & 0.21 \\
\hline 2 & B & 47.46 & 1351 & 75.65 & 22481.1 & 3.46 & 9.2 & 4.42 & 6.78 & 1.66 & 0.86 & 0.25 \\
\hline 3 & $\mathrm{C}$ & 53.25 & 1631 & 53.43 & 17341.9 & 3.25 & 6.5 & 4.86 & 12.76 & 2.54 & 0.38 & 0.22 \\
\hline 4 & $\mathrm{D}$ & 42.32 & 1387 & 38.14 & 14968.7 & 4.32 & 7.6 & 3.93 & 6.97 & 4.60 & 0.61 & 0.16 \\
\hline 5 & E & 51.56 & 1623 & 91.34 & $18,369.36$ & 5.56 & 6.1 & 4.21 & 13.95 & 4.76 & 0.47 & 0.09 \\
\hline 6 & $\mathrm{~F}$ & 43.50 & 1285 & 54.3 & 18881.7 & 3.50 & 5.9 & 4.65 & 5.49 & 3.36 & 0.53 & 0.08 \\
\hline
\end{tabular}

4.1.2 Initial investment allocation plan First, the collected data of the 6 companies are normalized, and the entropy method is used to calculate the standard value and weight of each indicator. evaluation index, which is helpful for multiple evaluations The horizontal comparison between objects, the calculation process is diversified and easy to understand, the TOPSIS method makes full use of the original data, inputs all the original data into the calculation model, based on objective data, objectively reflects the authenticity of the evaluation results, and objectively reflects It does not need to evaluate the gap and pros and cons between objects The disadvantage is that the accuracy of the original data is higher, and the calculated results of the changed data may differ greatly, which does not match the real results.

\section{Empirical analysis}

Six county-level power supply companies under a certain regional power company are selected as the research objects, combined with optimization technology methods, optimized and analyzed for each power supply company's power grid investment allocation in the next year. Details are as follows:

4.1.1 Nearly three years, a regional power company distribution network the amount of investment increased year by year, is expected to 2020 Nian 6 county-level power supply enterprise investment amount is expected to reach 30.2 billion yuan. Through research on the indicator data of various companies, the actual data collected are as follows:

Then comprehensively evaluate the actual data and weight determination results of each indicator. According to the above calculation company, the initial investment distribution ratio of each unit's power grid is obtained. The calculation results are as follows: 
Table3. Initial investment distribution table

\begin{tabular}{|l|l|l|l|}
\hline $\begin{array}{c}\text { Serial } \\
\text { number }\end{array}$ & $\begin{array}{c}\text { company } \\
\text { name }\end{array}$ & $\begin{array}{c}\text { Initial investment } \\
\text { distribution } \\
\text { coefficient }\end{array}$ & $\begin{array}{c}\text { Initial } \\
\text { investment } \\
\text { allocation } \\
\text { amount (100 } \\
\text { million yuan) }\end{array}$ \\
\hline 1 & A & $10 \%$ & 3.02 \\
\hline 2 & B & $17 \%$ & 5.13 \\
\hline 3 & C & $18 \%$ & 5.44 \\
\hline 4 & D & $19 \%$ & 5.74 \\
\hline 5 & E & twenty one $\%$ & 6.34 \\
\hline 6 & F & $15 \%$ & 4.53 \\
\hline
\end{tabular}

According to the principle of the method, sorting according to the size of the posting progress, the larger the closeness value, the better the solution; the smaller the closeness value, the worse the solution. The areas with relatively large progress are the areas with the best physical assets diagnosis and evaluation. Because area A is the best physical asset diagnosis and evaluation result.

\section{Conclusion}

This paper presents an optimization method for power grid infrastructure investment allocation decision based on entropy weight method. Carrying out fairness evaluation and optimization of investment allocation quotas to further improve the rationality and scientificity of power grid investment allocation quotas for power supply companies; solve the investment management and control problems encountered by power grid companies in actual work, and can adapt to current reform and development requirements and improve quality to meet the needs of efficient development, achieve precise investment and reasonable allocation, and improve the ability to optimize resource allocation and comprehensive efficiency.

\section{References}

1. Li Meng, Li Xiaodong. Research on the investment allocation model of power grid companies based on investment capacity $[\mathrm{J}]$. Northeast Electric Power Technology,2016,37(01): 19-23+33.

2. $\mathrm{Li} \mathrm{Ke}, \mathrm{Fu}$ Guanghui, TIAN Chun Zheng, Yu Hao positive, Li Cheng. Based on historical investment performance of investment allocation method with network and Project Selection [J]. Computing Technology and Automation,2019,38 (03): 33-38.

3. Qi Yongwei, Yang Ling. Research on the Grid Investment Scale Allocation Model Considering Multiple Factors [J]. Journal of Science \& Technology Economics,2019,27(27): 203-204.

4. Zhang Qi, Jia Mengyu. Research on rural power grid investment allocation decision based on neural network evaluation $[\mathrm{J}]$. Electric Power Big Data,2019,22(09): 72-78.

5. Ma Qian, Chen Lijun, Wang Jing, Jiang Nian, Jiang Wenjian. Optimal practice of annual grid investment plan based on Gini coefficient verification [J]. Power Supply and Consumption, 2017, 34(09): 37-40+45.
6. Qi Yong, Yang Chunhui, Zhang Ying before, Li Wen Yu, Fang Caixia. Investment allocation model and investment capacity calculation model to adapt to the reform of the electricity transmission and distribution [J]. Power \& Energy,2017,38 (04): 424427. 